\title{
Research on the Run-through Cultivating Modes for Undergraduates, Postgraduates and Doctoral Students in the Course of Cultivating Elite Talents
}

\author{
Yingxi Zheng \\ University of Electronic Science and Technology of China, \\ School of Electronic Engineering \\ Chengdu, China \\ Email: zhengyingxi@uestc.edu.cn
}

\begin{abstract}
In this paper, the author not only discusses the runthrough training modes for undergraduates, postgraduates and doctoral students in the course of cultivating elite talents, but also studies the current situations of cultivating talents in universities and colleges at home and abroad, and further analyzes the significance of run-through cultivation to those elites who may become the top-notch creative talents and technology leaders. Combined with the actual situation in our university, the author disserts the implementation methods of taking run-through cultivating modes in the process of fostering undergraduates, postgraduates and doctoral students, from which the author probes a series courses and sets a more prefect cultivating system for elite talents. Relevant ideas and methods are available for reference.
\end{abstract}

Keywords-Undergraduates, Postgraduates; Doctoral Students; Elite Talents; Run-through Cultivating Modes

\section{CURRENT SITUATION OF THE RUN-THROUGH CULTIVATING MODES FOR UNDERGRADUATES, POSTGRADUATES AND DOCTORAL STUDENTS}

In china's education, the talents cultivation usually carries out a three-staged training, which are undergraduates, postgraduates and doctoral students. Generally, the cultivating period for undergraduates is 4 years, postgraduates 2-3 years, and doctoral study 3-4 years, therefore, at least 10 years will be needed if a student who intends to complete all his study. Meanwhile, nowadays, with the rapid development of China's economy, the demand for innovative talents is increasing, so the traditional division for talents cultivation has not been able to meet the needs of rapid training of innovative elite talents [1]

The modern doctoral training originated the establishment of PhD. in the University of Berlin in the 19th century, which has created a training system for modern doctoral education. On the basis of the experience of cultivating Ph.D. in Germany, the United States also set a doctoral training mode with American characteristics. They are characterized by the implementation of flexible academic system, that is, according to the learning level to determine the awarded degree, and this approach is actually the talent implementation with runthrough training mode [2-3], or it is practicable to adopt this mode.

In recent years, focused on the top-notch innovative elite talents training, colleges and universities are actively exploring the run-through cultivating modes for elite talents in our country, for example, the full professional " $3+2+3$ " mode and successive bachelor-master-PhD program are firstly implemented in Sichuan University, which means that each of the outstanding students in 8 years can complete all of the study, as a result, in 2011, 100 selected students have conducted a pilot in Sichuan University. Besides, other colleges and universities are also trying to adopt the runthrough cultivating mode [4], such as the implementation of elite program in Hefei University of Technology, through collaboration among the universities, enterprises and research institutes, the innovative "bachelor-master-PhD" talent training mode has been formed [5]; The South China University of Technology has also designed a consistent training mode of "3+1+4" , which takes the run-through cultivating mode as an organic coherent [6]. In addition, the Beijing University of Technology initiates the "Elite Plan" in genius class [7]. The exploration of these universities provides a useful reference for the construction and implementation of the training system for bachelor and master and doctoral talents.

The cultivation of elite talents has always been the focus of research in colleges and universities at home and abroad. At present, some domestic colleges and universities also have several trial modes, most of which are in elite class, and each of student has different characteristics and effects. In previous years, our university also carried out this pilot, such as the foundation of the School of Elites. Now several years of work has been accumulated for valuable experience. President Yanrong Li of our university in his work report also stressed that our university should set the goal of talent training for industry leaders, and he said as a 985 project university, the cultivation for industry elite leaders should become our bounden duty and obligations.

Author Introduction : YingXi Zheng, master, engineer. Work Place: University of Electronic Science and Technology of China; Research Direction: Signal and Information Processing, engaged in graduate management.

Email: zhengyingxi@uestc.edu.cn. 


\section{SignificANCE Of THE Run-Through Cultivating MODE For UndERGRADUATES, POSTGRADUATES AND DOCTORAL STUDENTS}

The talent cultivation in higher education is a gradual process. Generally, the cultivation for undergraduates should lay a generous foundation for master and $\mathrm{PhD}$ study, while the training for postgraduates and doctoral students means preferring an interesting major to conduct an in-depth study and research on the basis of the professional knowledge, correct thinking method, and problem-solving ability that developed in the undergraduate stage. Therefore, it is a systematic and complete process to cultivate top talents. Besides, the traditional cultivating modes for undergraduates and postgraduates is relatively independent for lacking of cohesion and communication, and it doesn't form a systematic study either, as a result, the curriculum system in university can not fully support this mode. In addition, the curriculum system is often classified with majors that are little connection with related majors, thereby, it can't form a complete knowledge system of interdisciplinary subjects. The experience tells us that the development of each discipline cannot be single, but interrelated and overlapping, therefore, the intersection of knowledge system becomes the basic requirement of modern engineering education.

The run-through cultivating mode for undergraduates, postgraduates and doctoral students can embody the depth of discipline and intersection of knowledge system, which allows students to deepen their knowledge of the subject step by step and also set a goal to make the following study more targeted. Therefore, the run-through cultivating mode for undergraduates, postgraduates and doctoral students plays a vital significance for undergraduates to lay a good foundation for further study [7].

Our university has always been focusing on the cultivation of elite talents. From the undergraduate stage, there are various types of experimental classes for special training, such as the "Elite Class" for comprehensive cultivation, the "Lin Weigan Class" (Lin Weigan, a famous scientist who is the originator of China's microwave) for training excellent students in electronic information engineering, etc. For the goal of 985 Project University, the cultivation for elite talents is the key point.

Taking the "Lin Weigan Class" as an example, our university regards the innovative spirit of Lin Weigan as a guidance for students, and create a good study environment for students to help them to be the academic leaders. In some way, the cultivation of academic elites can not be separated from the corresponding environment and training mode. It is a beneficial way for the excellent students in "LinWeigan class" to adopt the run-through cultivating mode which breaks up the boundaries in the three learning stages and helps students grow rapidly. This mode can enable excellent students to have a solid discipline foundation, which allows students to enter the scientific research team in advance that is beneficial for later development of scientific research work [1]. The run-through cultivating mode is not only just allow students to choose the courses at different stages, but also to deeply study the curriculum setting and objectives in the current stages for sake of making the right training scheme and mode that is suitable for students to be academic leaders.

\section{MEASURES TAKEN UNDER THE RUN-THROUGH CULTIVATING MODE FOR UNDERGRADUATES, POSTGRADUATES AND DOCTORAL STUDENTS}

Based on the actual situation of the students, our university builds the seamless connection mode from undergraduates, postgraduates and doctoral students so that the students can arrange the learning content at different stages. For example, at the undergraduate stage, for senior students who have the ability to learn, they can take the postgraduate courses in advance, and at the postgraduate stage, students can prefer successive postgraduate and doctoral programs and directly pursue a doctoral study. This way for the outstanding students, can greatly shorten the whole process of learning, which may earlier qualify the abilities for being researchers or entrepreneurs.

In recent years, the number of $\mathrm{PhD}$. students, bachelor- $\mathrm{PhD}$. students and master-PhD. Students are increasing, while the traditional $\mathrm{PhD}$ students decrease, which reflects that the runthrough cultivating model is being adopted by more and more excellent students. In the past, to a certain degree, most students enrolled by all kinds of examinations have incomplete knowledge structure and poor coherence, so the systematization of knowledge is far from the depth of application of discipline and the requirement of solving complex engineering problems. The run-through cultivating mode can make good use of the coherence of the academic system, systematic study, rapid improvement of the research ability, and help the excellent students grow rapidly.

\section{A. Improve the management system, and build a good cultivating system and operating mechanism for undergraduates, postgraduates and doctoral students}

Formulating related management regulations is the primary work to better recommend this cultivating mode [8]. In recent years, our university has gradually made a number of related policies and management measures to publicity, such as "Implementation Methods for Outstanding Undergraduates Pursuing Master Study", "Regulations for Master-PhD. Study" and "Seminar Summery for the Trial Run-through Cultivating Mode", etc.

\section{B. Diversity of the Students Selection}

Now our university adopts methods that the undergraduates can choose postgraduate courses in advance or be doctoral students after obtaining bachelor' s degree, and a continuous project that involves postgraduate and doctoral study. The selection for Junior and senior students are in the same period. At this stage, student's interest in study, scientific research ability, ideological character as well as the independent living ability are gradually mature, and the goal for future career development is gradually clear, so the development of their future goals and our training norms and mechanisms is into a natural process. Apart from helping the students in our university, the policies under the run-through cultivating mode are also beneficial to attract some excellent students from other universities, which can help these students with different 
academic edge early adapt to learning through the tutor's remote guidance.

\section{Curriculum Integration}

Cultivating top-notch creative talents means providing the right teaching methods for those students who are with strong learning ability. The traditional cultivating mode gives consideration to different students, while for the excellent students, learning program setting needs to match their learning ability so as to meet the larger space for their future development.

The primary task of the run-through cultivating mode is to open courses to all students. The curriculum should be open to students with different learning abilities and requirements, and fully embody students-centered educational thoughts. For undergraduates with strong learning ability, they can even take courses directly from the doctoral level, and they can also take courses in many different subjects that lay a broad and profound foundation for their future development and provide support for their participation in high-level scientific research in the senior year. On this basis, the run-through mode can achieve the series of courses to improve the efficiency of courses [9].

\section{EfFect Of The Run-Through Cultivating Mode}

Since the implementation of elite talents training strategy in our university, many run-through modes have been carried out to offer good channels for excellent students and now those modes also have begun to exert effects. The implementation for undergraduates choosing courses in advance has been last 2 years in our university, and the program of bachelor- $\mathrm{PhD}$ and successive postgraduate and doctoral study has been conducted more than 5 years. The period for doctoral students training has been shortened, and most of the students who have been in direct and successive postgraduate and doctoral method are able to graduate within 4-5 years. In recent years, the number and quality of the papers that published by doctoral students has been improved a lot, such as in this year, the number of papers published in the SCI Journal are 2.98 per capita, which increases 0.59 compared with 2014 [10].
It is expected that in the future, the effect of this mode will be more and more fully reflected, and the emergence of talents will become a normal.

\section{CONCLUSION}

There is no fixed mode and method for talent cultivation, but how to optimize the allocation of educational resources and cultivate the top-notch talents needed to be explored continuously by colleges and universities. Based on the actual situation in our university, this paper probes the educational mode of bachelor-PhD. and successive postgraduate and doctoral study. And the excellent students can study in advance, shorten learning period, as well as improve leaning efficiency through the run-through cultivating mode. Under the guidance of learning resources and good environment, supports and guarantees should be better provided for the training of the new type high-quality innovative talents.

\section{REFERENCES}

[1] ZhiHong Zhang, Chunqing Liu local colleges and universities-Shuo-BO education integration of innovative talent training mode exploration, 2017.

[2] Osmo Kivinen, Sakari Ahola, towards the European Model of postgraduate training, University of Turku, in Report 50, 1999.2, 3, \$number.

[3] U.S. Department of Education,Digest of Education Statistics, 1998.

[4] Sichuan National first 8-year undergraduate and master's and doctoral company, [2013-03-21]. http://www. newssc. org.

[5] Wentao $\mathrm{Wu}$ and so on, collaborative innovation to achieve this-ShuoBO integrated Innovative talent training, evaluation and management, 2014.

[6] lingXing, ZhongLi, undergraduate and master's and doctoral integration of innovative talent training model research, degree and postgraduate education, 2012.

[7] Shu Cao, "integrative" innovative talent training model, China University of Science and Technology, 2014.

[8] Jingyi Wu etc, undergraduate and master's and doctoral courses integration and cross talent training, higher engineering education research, 2015.

[9] What is the core of the integration of "undergraduate and master's and $\mathrm{PhD}$ " courses, higher education and reform exploration, 2016.

[10] A statistical report on the cultivation of doctoral graduates in the 20162017 academic. 